periments dealing with the latter are being carried out, but this research note deals mainly with an examination of all the variables which might affect the results of pruning experiments and other treatments and an investigation of the resinification of knots as a process associated with the ageing of the stem. The results of the study show that the normal course of resinification can be regarded as beginning in one of two ways, depending on whether a branch dies before heartwood starts to form in the stem or heartwood formation has begun. The observations and analysis of the results are well described and discussed. They form a practical basis to take the subject a step further, that is, to relate it to time and height of pruning and, of course, to economics. This paper is a very useful contribution to the questions of when, how and to what extent resinification of a knot takes place.

\section{Enrico Fermi School of Physics:}

\section{Summer Courses}

THE International School of Physics "Enrico Fermi" is organizing five summer courses in physics at the Villa Monastero, Varenna sul Lago di Como. The subjects of the courses will be: (1) space exploration and the solar system, June 4-16; (2) advanced plasma theory, July 9-21; (3) elementary particles, July 23-August 4 ; (4) dispersion and absorption of sound by molecular processes, August $6-18$; (5) star evolution, August 20-September 1. Further information can be obtained from Prof. S. Olbert, Massachusetts Institute of Technology, Cambridge 39, Massachusetts (course 1); Prof. M. Rosenbluth, General Atomic Division, General Dynamics Corporation, P.O. Box 608, San Diego 12, California (course 2); Prof. M. Conversi, N.P. Division, CERN, Geneva 23 (course 3); Prof. D. Sette, Cattedra di Fisica, Facoltà di Ingegneria, Via Eudossiana 18, Rome (course 4); Prof. L. Gratton, Laboratori Nazionali di Frascati, Casella Postale N. 65, Frascati, Rome (course 5).

\section{University News:}

London

THE title of professor of experimental physics has been conferred on Dr. W. Ehrenberg and that of professor of electrochemistry on Dr. D. J. G. Ives, in respect of their posts at Birkbeck College.

Dr. A. Cameron has been appointed to a readership in mechanical engineering, tenable at the Imperial College of Science and Technology, and Dr. $\mathrm{K}$. Fotherby has been appointed to a readership in chemical pathology, tenable at the Postgraduate Medical School. The title of professor has been conferred on Dr. W. Bowen Bonnor (mathematics) in respect of the post held by him at Queen Elizabeth College. The titles of reader have been conferred on: Dr. P. G. Walker (chemical pathology) in respect of the post held by him at the Institute of Orthopædics; Dr. A. F. Cobbold (experimental physiology) in respect of his post at St. Thomas's Hospital Medical School; Dr. A. E. Kellie (biochemistry) in respect of his post at the Middlesex Hospital Medical School. Dr. J. F. Fowler has been appointed reader in physics at St. Bartholomew's Hospital Medical College.

\section{Announcements}

Arrong the newly appointed life peers announced on March 29 is Sir Alexander Todd, professor of organic chemistry in the University of Cambridge, and chairman of the Advisory Council on Scientific Policy.
Dr. Jean-Pierre Barrat, of the University of Caen, has been awarded the Adolph Lomb Medal of the Optical Society of America. The Medal is awarded to a person under thirty years of age who has made "a noteworthy contribution to optics".

THE Zoological Society of London has awarded the Edward Forbes Medal for scientific merit to Dr. Arthur James Cain, of the Department of Zoology, University of Oxford, and to Dr. Robert Aubrey Hinde, of the Department of Zoology, University of Cambridge. The Medals - awarded to persons under forty years of age for distinguished work in zoologywill be presented by H.R.H. the Duke of Edinburgh, president of the Zoological Society of London, immediately following the annual general meeting of the Society, which will be held on April 27.

THE office of the International Society for Tropical Ecology has moved from Allahabad to Varanasi (India). All communications should be addressed to Prof. R. Misra, Banares Hindu University, Varanasi, India.

A meeting of the British Society of Soil Science will be held at the London School of Economics, Houghton Street, W.C.2, during April 16-18. There will be three sessions: (a) productivity and soil type; (b) microbiology of podzols; (c) micro-organisms in relation to nutrient availability in soil. Further information can be obtained from Dr. D. V. Crawford, University of Nottingham School of Agriculture, Sutton Bonington, Loughborough.

The National Engineering Laboratory, East Kilbride, is holding open days during May 2-4. Developments on show in the field of mechanical engineering will include: the application of air-lubricated bearings to machine tools; research on the production of new materials by the application of very high pressures; facilities for research on creep of metals; new automatic measuring techniques; further data on the cold extrusion of steel; advances in pump and fan design. Further information can be obtained from the Director, National Engineering Laboratory, East Kilbride, Glasgow.

A SYMPOSIUM on "The Protection of Structural Steel" will be held in the University of Birmingham on April 18. The programme will include: the hotdip galvanizing of structural steel; the properties of hot-galvanized steel; galvanized structures for power transmission; the use of hot-galvanized steel in building; the design and protection of tubular steel structures; the application and uses of zinc spraying; economic aspects of protection. Further information can be obtained from the Zine Development Association, 34 Berkeley Square, London, W.1.

Errata. In the article entitled "Fatty Acids in Recent and Ancient Sediments and Petroleum Reservoir Waters" (Nature, 193, 744; 1962), by J. E. Cooper, the fifth sentence in the second complete paragraph on p. $\mathbf{7 4 6}$ should read: "Intermediates of this type derived from even-numbered acids could react to give a mixture of odd-numbered acids and paraffins as a product".

IN Table 1 of the communication entitled "Inhibition of Dopamine $\beta$ Oxidase by Adrenalone", by $\mathbf{M}$. Goldstein and J. F. Contrera (Nature, 192, 1081; 1961), cols. 1, 2 and 3 should be headed Dopamine, Adrenalone and Epinine, respectively; the last insertion in col. 2 should read $1 \cdot 2$, and the second in col. 3 should read $3 \cdot 2$. 